\title{
Anthelmintic resistance in ovine gastrointestinal nematodes in inland southern Queensland
}

\author{
M Lyndal-Murphy, WK Ehrlich and DG Mayer*
}

Objective To establish the prevalence of anthelmintic resistance in ovine gastrointestinal nematodes in southern Queensland.

Design An observational parasitological study using the faecal egg count reduction test.

Methods Sheep farms $(n=20)$ enrolled in this study met the twin criteria of using worm testing for drench decisions and having concerns about anthelmintic efficacy. On each farm, 105 sheep were randomly allocated to one of six treatment groups or an untreated control group. Faecal samples were collected on day 0 and days 10-14 for worm egg counts and larval differentiation. Single- and multi-combination anthelmintics, persistent and non-persistent, oral liquid or capsule, pour-on and injectable formulations were tested. Monepantel was not tested. Farmers also responded to a questionnaire on drenching practices.

Results Haemonchus contortus was the predominant species. Efficacy $<95 \%$ was recorded on $85 \%$ of farms for one or more anthelmintics and on $10 \%$ of farms for six anthelmintics. No resistance was identified on three farms. The 4-way combination product was efficacious ( $n=4$ farms). Napthalophos resistance was detected on one farm only. Resistance to levamisole ( $42 \%$ of farms), moxidectin injection (50\% of farms) and the closantel/abamectin combination (67\% of farms) was identified. Moxidectin oral was efficacious against Trichostrongylus colubriformis, which was predominant on only one farm. Of the farms tested, $55 \%$ ran meat breeds, $60 \%$ dosed more than the recommended dose rate and $70 \%$ always, mostly or when possible practised a 'drench and move' strategy.

Conclusion This level of anthelmintic resistance in southern Queensland will severely compromise worm control and force increased use of monepantel.

Keywords anthelmintic resistance; faecal egg count reduction test; Haemonchus contortus; nematode control; sheep

Abbreviations $A B A$, abamectin (non-persistent $M L$ ); $A R$, anthelmintic resistance; $B Z$, benzimidazole; $C L O S$, salicylanilides and substituted nitrophenols (persistent closantel); epg, eggs per gram; FECRT, faecal egg count reduction test; IVER, ivermectin (nonpersistent $M L$ ); LD, larval differentiation; LEV, levamisole; $M L$, macrocyclic lactones (abamectin, ivermectin, moxidectin); MPL, monepantel (amino-acetonitrile derivative); MOX, moxidectin (persistent ML); NAP, naphthalophos

Aust Vet J 2014;92:415-420

doi: $10.1111 /$ avj.12250

${ }^{*}$ Corresponding author.

Department of Agriculture, Fisheries and Forestry, Eco-Sciences Precinct, Dutton

Park, Brisbane, Queensland 4102, Australia; David.Mayer@qld.gov.au
A nthelmintic resistance (AR) is a serious threat to the productivity and viability of sheep enterprises in the inland subtropical summer rainfall region of southern Queensland, Australia. AR compromises the efficient regional control of endemic disease caused by gastrointestinal nematodes, predominantly Haemonchus contortus. Deaths of between $10 \%$ and $50 \%$ of weaner stock can occur from approximately 10 days after a significant rainfall event in summer and even during the cooler months of the year. ${ }^{1}$ Trichostrongylus colubriformis is also endemic in this region, but rarely the cause of clinical disease. It ranks in importance after $H$. contortus and the highly pathogenic, although of very low incidence, Oesophagostomum columbianum.

Although contrary to the best-practice recommendations of promulgated regional programs, ${ }^{2}$ applications of persistent anthelmintic treatments are central to worm control in this region. Typically, farmers treat when signs of infection become clearly visible in the mob. Failure of an anthelmintic at this crucial stage of the disease, especially in high-risk seasons, results in a per-head morbidity cost of $\mathrm{A} \$ 5.93^{3}$ and a mortality cost equal to the current year's production plus the capital cost of replacing lost stock. Treatment of the whole mob is practised particularly for aged wethers, and ewes at weaning, often when there are only low numbers of gastrointestinal nematodes in refugia (populations of worms either in the host or on pasture that escape selection by the current drug treatment). ${ }^{4}$

In Queensland, the levels of AR have increased over time, ${ }^{5-7}$ as has the incidence at the national level. ${ }^{8-10}$

In favourable (good) seasons, farms need to maximise productivity to offset the poorer returns of dry seasons. The very wet conditions in 2010 resulted in severe, uncontrolled infections and numerous farmer reports of drench failure at a time when the value of sheep and lambs was historically high, compounding the economic loss. The aim of this study, initiated in 2011, was to identify the levels of AR across southern Queensland on farms reporting perceived treatment failure.

\section{Materials and methods}

\section{The study}

We enrolled 20 farms across southern Queensland, in a line from Charleville (-26.405) east to Roma (-26.574) and Stanthorpe $(-28.620)$ and south to the border districts $(-29.042)$ of northern New South Wales for AR testing from November 2011 to May 2012 and January-February 2013. Farms were distributed across two rainfall zones: the 650-750 $\mathrm{mm}$ rainfall zone (Region 1) and the $350-650 \mathrm{~mm}$ zone (Region 2).

Testing targeted those farms that sourced the worm testing services of the Queensland Department of Agriculture Fisheries and Forestry and 
reported perceived treatment failure. Farms were invited to participate when their mob-average monitor worm test results were at least 400 eggs per gram (epg). A short questionnaire was used to gather information about on-farm drenching practices at the first farm visit.

This research was approved by the EcoSciences Precinct Animal Ethics Committee, approval number SA2012/02/376, 'Drench Resistance Survey'.

\section{Detection of $A R$ in vivo}

The faecal egg count reduction test (FECRT) was used to determine AR. ${ }^{11,12}$ Pre-drench (day 0) and post-drench (days 10-14) faecal egg counts (FEC) and larval differentiation (LD) to genera were used in the calculation of AR. On each farm, groups of 15 sheep were randomised to treatment groups $(\mathrm{n}=6)$ and a corresponding untreated control group. Allocation of sheep into groups was facilitated by uniquely numbered and coloured ear tags applied on day 0 . The number of anthelmintics tested on each farm ranged from 4 to 8 , with a median of 6 . Sheep were $6-36$ months old at testing; $55 \%$ of the flocks were meat breeds ( $44 \%$ in Region $1,64 \%$ in Region 2). Stocking rates averaged 2.0 and 0.2 sheep/ha in Regions 1 and 2, respectively.

\section{Anthelmintics tested}

The tested anthelmintics are listed in Table 1. Single- and multi-active combinations of narrow-, mid- and broad-spectrum anthelmintic actives were tested as oral liquid, oral bolus capsule, injectable and pour-on formulations of short-, mid- or long-acting persistency. A group of 15 sheep were shorn on day 0 as part of the testing procedure for the off-shears pour-on product. All anthelmintics were dosed at the manufacturer's recommended dose rate. Choice of anthelmintic to be tested on each farm was determined by farm history of usage and farmer's request to test a particular product. Monepantel (MPL) was not tested.

\section{Parasitology}

In the laboratory, 15 samples from each treatment group were subdivided into three groups of five each, ${ }^{13,14}$ with each subgroup analysed by the modified McMaster technique. Eggs were enumerated at $\times 40$ magnification with 1 egg equivalent to 40 epg of faeces. Bulk larval cultures were set up for each treatment group and incubated for 7 days at $27^{\circ} \mathrm{C}$. Differentiations of at least 100 infective larvae (L3) were carried out for each bulk culture. ${ }^{15}$

\section{Determination of $A R$}

Pre- and post-drench differentiated FECs of the treated and untreated groups of sheep were used in the calculation of AR and also to control for continuous larval development during the test evaluation period. ${ }^{16}$ Statistical analysis was carried out using GenStat Release 14 software package (VSN International Ltd., Oxford, 2013), with data analysis facilitated in an Excel spreadsheet. The reduction in FEC for each anthelmintic was calculated using the following formula:

Table 1. Anthelmintics tested in sheep in southern Queensland, Australia

\begin{tabular}{|c|c|c|c|c|c|}
\hline Type & Length of action & Active ingredient & Dose rate/body weight & Administration & Product \\
\hline Single & Short & $B Z$ & $1 \mathrm{~mL} / 5 \mathrm{~kg}$ & Oral & Alben $^{\circledR a}$ \\
\hline Single & Short & LEV & $1 \mathrm{~mL} / 10 \mathrm{~kg}$ & Oral & Nilverm ${ }^{\circledR}$ LV $^{b}$ \\
\hline Single & Short & NAP & $3 \mathrm{~mL} / 10 \mathrm{~kg}$ & Oral & Rametin $^{{ }_{c}}$ \\
\hline Single & Short & CLOS & $1 \mathrm{~mL} / 5 \mathrm{~kg}$ & Oral & Closicare $^{{ }_{a}}$ \\
\hline Single & Short & IVER & $2.5 \mathrm{~mL} / 10 \mathrm{~kg}$ & Oral & Paramax ${ }^{\circledR b}$ \\
\hline Single & Long & MOX & $1 \mathrm{~mL} / 20 \mathrm{~kg}$ & Injection & Cydectin $^{\circledR}$ LA injection ${ }^{a}$ \\
\hline 2-way & Short & BZ+LEV & $1 \mathrm{~mL} / 5 \mathrm{~kg}$ & Oral & Duocare ${ }^{\circledast_{a}}$ \\
\hline 3-way & Short & $B Z+L E V+A B A$ & $1 \mathrm{~mL} / 5 \mathrm{~kg}$ & Oral & $\begin{array}{l}\text { Triguard }^{\circledR d} \\
\text { Hat-Trick }^{\circledR d}\end{array}$ \\
\hline 4-way & Short & $\mathrm{BZ}+\mathrm{LEV}+\mathrm{ABA}+\mathrm{CLOS}$ & $1 \mathrm{~mL} / 5 \mathrm{~kg}$ & Oral & Q-drench ${ }^{\circledR e}$ \\
\hline & Long & $B Z+A B A$ & $1 / 40-80 \mathrm{~kg}$ & Capsule & Dynamax $^{\circledR \mathrm{d}}$ \\
\hline NAP mixes & Short & $\begin{array}{l}\text { NAP+BZ or } \\
\text { NAP+LEV or } \\
\text { NAP+BZ+LEV }\end{array}$ & Manufacturer's instructions ${ }^{f}$ & Oral & Rametin $^{\circledR c}$ \\
\hline
\end{tabular}

Primer: drench dosed concurrently with a persistent anthelmintic.

ABA, abamectin; BZ, benzimidazole; CLOS, closantel; IVER, ivermectin; LA, long-acting; LEV, levamisole; LV, low volume; MOX, moxidectin; NAP, naphthalophos

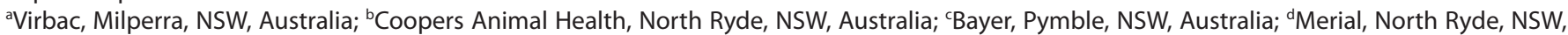
Australia; ${ }^{e} J u r o x$, Rutherford, NSW, Australia; ${ }^{f}$ Rametin sheep drench can be mixed on-farm with a BZ active. Mixing instructions come with the product and are available on the internet: see Bayer products at www.farmadvisor.com.au 


$$
\% \text { reduction }=100[1-(\mathrm{mt} 2 * \mathrm{mcl}) /(\mathrm{mc} 2 * \mathrm{mt} 1)]
$$

where $\mathrm{mcl}=$ mean epg control group pre-drench, $\mathrm{mc} 2=$ mean epg control group post-drench, $\mathrm{mtl}=$ mean epg treatment group predrench and $\mathrm{mt} 2$ =mean epg treatment group post-drench.

Resistance to an anthelmintic was inferred if the reduction in the arithmetic mean from the genera-corrected treatment group was $<95 \%$ at $10-14$ days after treatment and the lower $95 \%$ confidence limit was less than the $90 \%$ reduction level when compared with the control group. For the binary data (resistant or not, at the farm level), the confidence limits were estimated on the logit scale and then backtransformed onto the percentage scale, ${ }^{17}$ except for the 0 and $100 \%$ responses where the conservative (maximum possible) standard error was estimated using the theoretical variance assuming one positive value and adopted.

\section{Results}

\section{General results}

Testing was successfully completed on 20 farms. LD confirmed the predominance of $H$. contortus on 19 farms and T. colubriformis on only 1 farm (farm code 4).
Table 2. Proportion of sheep farms in southern Queensland, Australia, with resistance in Haemonchus contortus to anthelmintics tested

\begin{tabular}{lcccc}
\hline Anthelmintic & $\begin{array}{c}\text { No. farms } \\
\text { positive* }\end{array}$ & $\begin{array}{c}\text { Total no. } \\
\text { farms tested }\end{array}$ & $\begin{array}{c}\text { Overall } \\
\text { prevalence (\%) }\end{array}$ & $\begin{array}{c}95 \% \\
\mathrm{Cl}\end{array}$ \\
\hline BZ & 2 & 4 & 50 & $9-91$ \\
LEV & 8 & 19 & 42 & $20-67$ \\
NAP & 1 & 16 & 6 & $1-41$ \\
NAP+BZ or +LEV or & 0 & 3 & 0 & $0-62$ \\
$\quad$ BZ+LEV & & & & \\
BZ+LEV & 4 & 9 & 44 & $15-78$ \\
BZ+LEV+ABA & 4 & 10 & 40 & $13-74$ \\
BZ+LEV+ABA+CLOS & 0 & 4 & 0 & $0-49$ \\
CLOS & 3 & 5 & 60 & $16-92$ \\
CLOS+ABA & 12 & 18 & 67 & $39-86$ \\
MOX Oral & 6 & 6 & 100 & $66-100$ \\
MOX LA injection & 8 & 16 & 50 & $24-76$ \\
\end{tabular}

${ }^{*}$ Anthelmintic resistance identified.

$\mathrm{ABA}$, abamectin; $\mathrm{BZ}$, benzimidazole; $\mathrm{Cl}$, confidence interval; CLOS, closantel; LA, long-acting; LEV, levamisole; MOX, moxidectin; NAP, naphthalophos

Table 3. Undifferentiated group mean faecal egg counts (FEC) and efficacy of levamisole (LEV) and naphthalophos (NAP) anthelmintics against Haemonchus contortus on sheep farms in southern Queensland, Australia

\begin{tabular}{|c|c|c|c|c|c|c|}
\hline \multirow[t]{3}{*}{ Farm code } & \multicolumn{3}{|c|}{ LEV oral } & \multicolumn{3}{|c|}{ NAP oral } \\
\hline & \multicolumn{2}{|c|}{ FEC (epg) } & \multirow[t]{2}{*}{ Efficacy (\%) (Cl) } & \multicolumn{2}{|c|}{ FEC (epg) } & \multirow[t]{2}{*}{ Efficacy (\%) (Cl) } \\
\hline & Day 0 & Days 10-14 & & Day 0 & Days 10-14 & \\
\hline 1 & 2867 & 596 & $88(80-93)$ & 1735 & 66 & $98(87-99.8)$ \\
\hline 2 & 2893 & 53 & $99.3(95-99.9)$ & 4133 & 0 & 100 \\
\hline 3 & 1947 & 347 & 92 (84-96) & - & - & - \\
\hline 4 & 947 & 1467 & $98(82-99.7)$ & - & - & - \\
\hline 5 & 5960 & 1,187 & 84 (71-91) & 2173 & 53 & 98 (91-99.5) \\
\hline 6 & 3243 & 40 & 97 (89-99.3) & 4423 & 70 & 96 (71-99.4) \\
\hline 7 & 640 & 80 & $99.8(93-99.9)$ & 707 & 27 & $99.8(91-100)$ \\
\hline 8 & 2133 & 240 & 91 (81-96) & 3333 & 133 & 97 (89-99) \\
\hline 9 & 893 & 97 & $94(80-98)$ & - & - & - \\
\hline 10 & 2173 & 57 & 95 (32-99.6) & 1507 & 0 & 100 \\
\hline 11 & - & - & - & 757 & 0 & 100 \\
\hline 12 & 9573 & 1173 & $54(0-85)$ & 6507 & 53 & 99.8 (99.5-99.9) \\
\hline 13 & 307 & 0 & 100 & 600 & 0 & 100 \\
\hline 14 & 1400 & 437 & $67(0-95)$ & 3013 & 53 & $99.6(92-99.98)$ \\
\hline 15 & 920 & 493 & $45(0-87)$ & 1267 & 120 & 90 (50-98) \\
\hline 16 & 1213 & 0 & 100 & 467 & 0 & 100 \\
\hline 17 & 2213 & 27 & 98 (82-99.2) & - & - & - \\
\hline 18 & 663 & 13 & $98(90-99.6)$ & 693 & 0 & 100 \\
\hline 19 & 2353 & 17 & $99.8(96-99.9)$ & 1733 & 27 & 99.7 (98-99.9) \\
\hline 20 & 6480 & 153 & 98 (89-99.5) & 3947 & 0 & 100 \\
\hline
\end{tabular}

-, not tested. Farms 1-9 located in Region 1 with 650-750 mm average annual rainfall. Farms 10-20 located in Region 2 with 350-650 mm average annual rainfall.

$\mathrm{Cl}$, confidence interval; epg, eggs per gram. 


\section{The study}

Nine farms (farm codes 1-9) were located in Region 1 and 11 (farm codes 10-20) in Region 2. On two farms, some of the control group sheep presented with high FECs (e.g. 18,480 epg; farm code 18) and lethargy. Control groups were therefore salvaged-drenched and withdrawn from the test on animal welfare grounds before post-drench samples could be collected. For these farms, the day 0 control FEC and LD were substituted for the days 10-14 control FEC and LD in the resistance calculations. Formulations tested were oral (20 farms), injectable (16 farms), bolus capsule (5 farms) and pour-on (1 farm).

\section{Anthelmintic resistance}

For the proportions of properties showing AR, there was no significant effect of region $(\mathrm{P}=0.30)$ and no region by treatment interaction $(\mathrm{P}=0.88)$, indicating that the treatments were of equal efficacy in both regions. For $H$. contortus, 17 of the 20 farms presented with resistance to one or more anthelmintics. Resistance was seen to one (2 farms), two (5 farms), three (3 farms), four ( 3 farms), five ( 2 farms) and six (on 2 farms) anthelmintics; 3 farms showed no resistance to any of the anthelmintics tested.
As shown in Table 2, the 4-way active formulation (benzimidazole (BZ), levamisole (LEV), abamectin (ABA) and closantel (CLOS)) was efficacious against $H$. contortus populations on all 4 farms tested. Naphthalophos (NAP) was effective against $H$. contortus populations on 15 of 16 farms and NAP combinations with non-macrocyclic lactone (ML) anthelmintics were effective on the 3 farms tested. A high prevalence of AR in $H$. contortus populations was identified for all other drugs.

Of the 8 farms that carried populations resistant to LEV, 5 were in Region 1, and 3 in Region 2 (Table 3 ). The H. contortus populations on 3 of 5 farms tested were resistant to CLOS $(37.5 \mathrm{~g} / \mathrm{L})$ and on 12 of 18 farms resistant to the combination of CLOS $(50 \mathrm{~g} / \mathrm{L})+$ ABA (Table 4).

For the ML anthelmintics (Table 4), H. contortus populations were resistant to moxidectin (MOX) oral on all 6 farms tested and 8 of 16 farms carried $H$. contortus that was resistant to MOX LA. A pyraclophos primer dosed concurrently with the MOX LA injection was tested on farm code 16 , which had a perceived history of MOX oral resistance, showing 100\% effectiveness (Table 4).

Table 4. Undifferentiated group mean faecal egg counts (FEC) and efficacy of closantel-abamectin (CLOS + ABA) combination and moxidectin (MOX) long-acting (LA) anthelmintics against Haemonchus contortus on sheep farms in southern Queensland, Australia

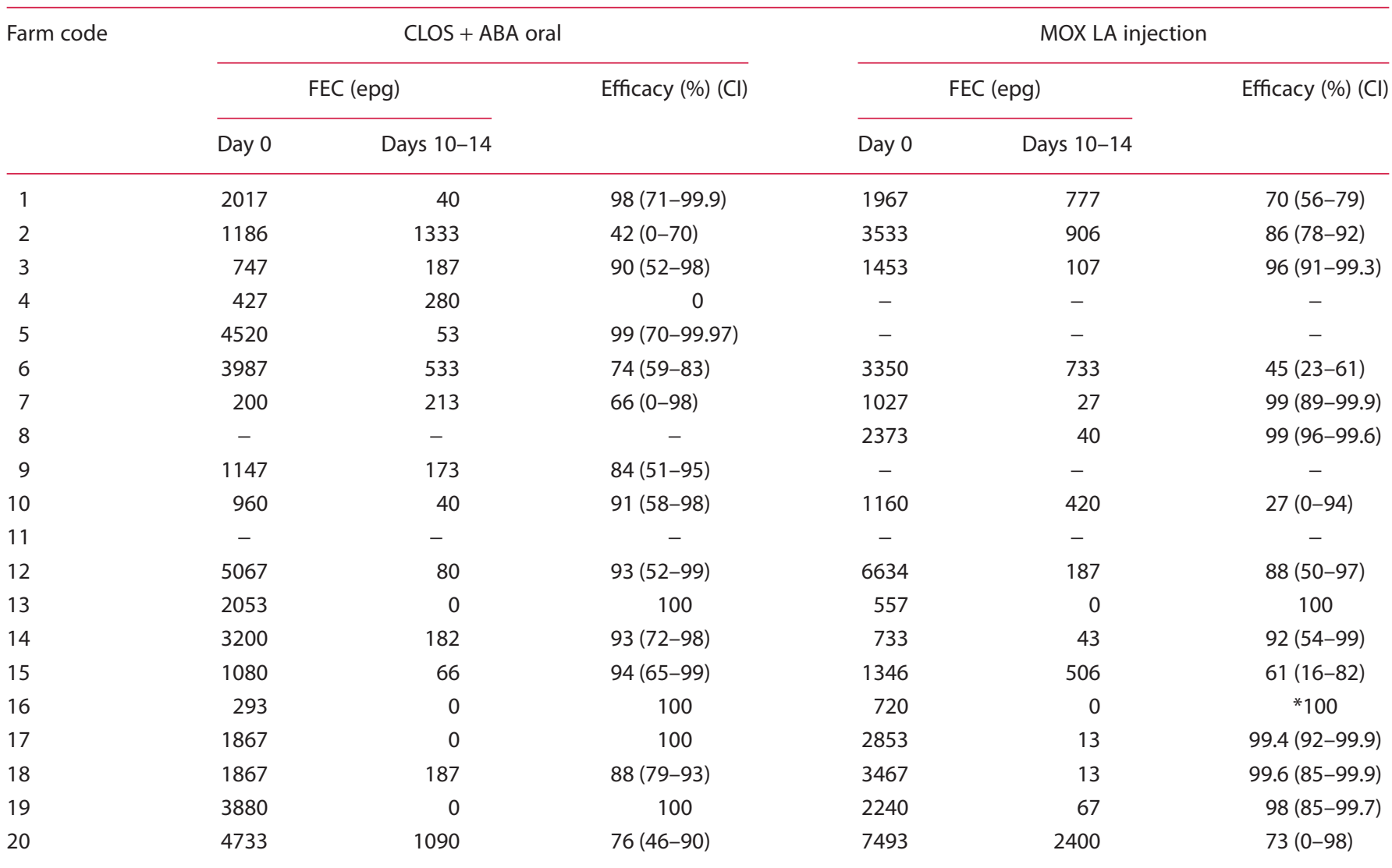

*Pyraclophos primer drench dosed concurrently with the MOX LA injection.

-, not tested. Farms 1-9 located in Region 1 with 650-750 mm average annual rainfall. Farms 10-20 located in Region 2 with 350-650 mm average annual rainfall.

$\mathrm{Cl}$, confidence interval; epg, eggs per gram. 
Single- (BZ and IVER) and multi- (BZ + ABA) active adult boluses, with or without a primer drench, were tested on 5 farms. Only the BZ bolus with a LEV primer drench was effective (farm code 2) (data not shown).

The incidence of T. colubriformis populations across farms and treatment groups was variable and results are indicative only for 3 of the 4 farms, as the resistant populations were less than $25 \%{ }^{18}$

\section{Drenching practices}

All farms used laboratory testing services to determine when to treat and $85 \%$ reported also drenching sheep on visual indicators of worms. The number of anthelmintics given to weaners over the past 12 months was, on average, 4.6 (range 1-12) in Region 1 and 1.7 (1-3) in Region 2; 75\% of farms were drenching more frequently (56\% in Region 1; $90 \%$ in Region 2) than 5 years ago; $85 \%$ had previously changed anthelmintics because of a perceived resistance problem, and $70 \%$ of farms believed that resistance is still a problem. A total of $85 \%$ of farms dosed anthelmintics to the weight of the heaviest animal in the mob rather than to the average weight and 60\% (44\% in Region 1; $73 \%$ in Region 2) dosed higher than the manufacturer's recommended dose rate to better control worms when AR was present. After drenching, $70 \%$ of farms always or usually moved sheep to pastures that had been spelled, grazed with cattle or cropped.

\section{Discussion}

The FECRT identified widespread AR in gastrointestinal nematodes (predominantly $H$. contortus) across the target region, with resistance to LEV, CLOS and MOX, either alone or in combination. The nonpersistent formulated 4-way combination of BZ, LEV, ABA and CLOS was highly efficacious. NAP was efficacious on all but one farm and MOX was effective against T. colubriformis infections identified on some farms.

These results are broadly similar to previous reports for $H$. contortus endemic regions. Nielson ${ }^{19}$ reported resistance in $H$. contortus to MOX (74\% of farms), CLOS (77\% of farms) and LEV (57\% of farms), and NAP resistance was considered to be 'rare' in the northern higher rainfall region (New England) of New South Wales. Walker et al. reported moxidectin-resistant $H$. contortus on $50 \%$ of farms tested in drier regions of the central western New South Wales, ${ }^{20}$ which approximately correspond to Regions 1 and 2, respectively, in this study. Baker et al. reported $83 \%$ efficacy of the formulated 4 -way combination against $H$. contortus, ${ }^{21}$ whereas it was $100 \%$ efficacious in this study, although the number of farms was small $(n=4)$. Efficacy for NAP was $>95 \%$ on all but one farm and that negative result requires confirmation through retesting. The only previously reported case of NAP resistance in H. contortus of sheep was on an agricultural college in south-east Queensland in $1981 .^{5}$

The high levels of ML resistance reported in this study, although not unexpected, were confronting, especially on the extensively-managed farms in Region 2. Typically, these farms drench once or twice each year, and less in dry seasons. Persistent anthelmintics are preferred because mobs are not readily mustered and both the onset and amounts of general rainfall are extremely variable. ${ }^{1} \mathrm{MOX}$, increasingly the more potent long-acting injectable formulation, and the ABA-
CLOS $(50 \mathrm{~g} / \mathrm{L})$ combination are frequently dosed to ewes at the prelambing drench and to other classes of stock during summer when storms can isolate sheep on elevated ground for weeks to months at a time with resultant high stock losses. ${ }^{1}$ Although there will always be a lag phase between best-practice drug usage and industry adoption, it is unfortunate that MOX has rarely been used 'in combination' to delay the development of $\mathrm{AR}^{22,23}$ The appearance of ML resistance in $H$. contortus is related, in part, to its inheritance of resistance as a dominant trait $^{24}$ and to excessive frequency of treatment. ${ }^{9}$

In both regions, LEV has been used without reports of overt treatment failure for more than 30 years in areas where rainfall is often low and temperatures are often $\geq 35^{\circ} \mathrm{C}$, leaving few larvae on pasture. In this environment, LEV is considered by industry to be an inexpensive alternative to the formulated 2-, 3- and 4-active combination drugs. It may be that LEV dosed in low-refugia seasons is an appropriate choice. Juvenile larvae (L4) in the host are refractory to this anthelmintic and escape selection for resistance. ${ }^{18}$ In addition, inheritance of resistance to LEV in $H$. contortus is an autosomal recessive trait that responds slowly to drug selection..$^{24,25}$ In contrast, when LEV is used in combination during low-refugia seasons the overwhelming risk is resistance to each of the individual actives. Tellingly, in this study LEV-resistant $H$. contortus are now common across the region.

Frequency of treatment, under-dosing and incorrect drenching technique $^{26}$ have often been regarded as causes of AR. Increasing the dose rate, as practiced by many farms in this study, is a recognised method of increasing efficacy ${ }^{27}$ and has been successfully used to produce greater efficacy of the CLOS (50 g/L)-ABA combination, subsequent to failure of the lower dose rate $(37.5 \mathrm{~g} / \mathrm{L})$. Of greater concern in this region is the adoption, in response to treatment failures, of the 'drench and move' strategy where sheep are moved to low-infectivity pastures or crops after drenching. Although this strategy reduces the re-infection rate and extends the period between required drug treatments, it is considered highly selective for AR. ${ }^{22}$

Gastrointestinal nematodes have the genetic potential to respond rapidly to drug selection and most commonly disseminate their resistant genes through host movement between farms. ${ }^{28}$ Two stark examples were uncovered in this study. Two farms in Region 2 ran cattle enterprises up until 2-3 years ago when they both changed to meat breeds of sheep. These farms now present with severe resistance profiles, missing the opportunity to be AR-free. Both farms sought advice from industry on the most appropriate anthelmintic for the quarantine treatment. Of further concern is that the farmers in this study were unaware of the WormBoss ${ }^{2}$ recommendations for bestpractice quarantine drenching, ${ }^{29}$ including the use of MPL and of the recommendations for MPL use in this region. ${ }^{25}$

Treatment failure is usually the catalyst for farmers to source specialist services and the farmers in this study were no exception. Although they embraced worm testing, they displayed disinterest in initiating the AR testing, a sentiment also identified nationally. ${ }^{30}$ FECRT is cumbersome, labour-intensive and expensive, both on-farm and in the laboratory. There is inherent variation in the repeatability of the test $\mathrm{t}^{31}$ exacerbated by insensitive methods used for performing $\mathrm{FECs}^{32}$ and results in only a reasonable assessment of true resistance. ${ }^{33}$ The farmers in this study preferred to rely on a post-drench worm test as a guide to anthelmintic 
efficacy and efficiency of treatment application. These farmers consider the post-drench worm test inexpensive, easy to use, produces results that are easily understood and fits well with farm managment. ${ }^{34}$

\section{Conclusion}

This study's results clearly demonstrate the serious nature of AR on sheep farms across southern Queensland and the border districts. Increasingly, severe resistance on most farms will force greater use of the highly effective anthelmintic, MPL. The urgent need is to communicate to farmers the best-practice management of this anthelmintic to prolong its useful life and that of still currently effective anthelmintics.

\section{Acknowledgments}

We acknowledge the expert technical assistance provided by Judy Gemmell, and that of Lloyd Dunlop and John Scriven for the farm component of this study.

This study was co-funded by Meat and Livestock Australia and Australian Wool Innovation.

\section{References}

1. Swan RA. The epizootiology of haemonchosis in sheep. Aust Vet J 1970;46:485492.

2. Maxwell D, Love S, Lyndal-Murphy M. WormBoss worm control program: Qld/ NSW summer rainfall/slopes and plains. 2012. www.wormboss.com.au/ programs/slopes-plains.php Accessed July 2013.

3. Sackett $D$, Holmes $P$, Abbott $K$ et al. Assessing the economic cost of endemic disease on the profitability of Australian beef cattle and sheep producers. Final Report, project AHW-087. Meat and Livestock Australia, Sydney, 2006; 133.

4. Besier RB. Refugia-based strategies for sustainable worm control: factors affecting the acceptability to sheep and goat owners. Vet Parasitol 2012;186:2-9.

5. Green PE, Forsyth BA, Rowan KJ et al. The isolation of a field strain of Haemonchus contortus in Queensland showing multiple anthelmintic resistances. Aust Vet J 1981;57:79-84.

6. Le Jambre LF, Geoghegan J, Lyndal-Murphy M. Characterization of moxidectin resistant Trichostrongylus colubriformis and Haemonchus contortus. Vet Parasitol 2005;128:83-90.

7. Knox M, Lyndal-Murphy M, Kotze A et al. Macrocyclic lactone resistance in an isolate of ovine Trichostrongylus colubriformis from North Queensland. In: Proceedings of the 23rd Conference of the World Association for the Advancement of Veterinary Parasitology, Buenos Aires, 2011;46.

8. Overend DJ, Phillips ML, Poulton AL et al. Anthelmintic resistance in Australian sheep nematode populations. Aust Vet J 1994;71:117-121.

9. Besier RB, Love SCJ. Anthelmintic resistance in sheep nematodes in Australia: the need for new approaches. Aust J Exp Agric 2003;43:1383-1391.

10. Love S. Prevalence of anthelmintic resistance in sheep worms in Australia: a thumbnail sketch. In: Proceedings of the Australian Sheep Veterinary Conference. AVA, Adelaide, 2011;47-50.

11. Coles GC, Bauer C, Borgsteede FHM et al. World Association for the Advancement of Veterinary Parasitology (W.A.A.V.P.): methods for the detection of anthelmintic resistance in nematodes of veterinary importance. Vet Parasitol 1992;44:35-44.

12. Pepper PM, Swain AJ, Lyndal-Murphy M. Using simulation techniques to investigate methods to determine resistance of helminths to anthelmintic treatment. In: Proceedings of the MODSIM 2003 International Congress on Modeling and Simulation, Townsville, QLD, 2003;4:1580-1585.
13. Baldock FC, Lyndal-Murphy M, Pearse B. An assessment of a composite sampling method for counting strongyle eggs in sheep faeces. Aust Vet $J$ 1990;67:165-167.

14. McKenna PB. How do you mean? The case for composite faecal egg counts in testing for drench resistance. NZ Vet $J$ 2007;55:100-101.

15. Hutchinson G. Nematode parasites of small ruminants, camelids and cattle: diagnosis with emphasis on anthelmintic efficacy and resistance testing. Australian and New Zealand Standard Diagnostic Procedures. SCAHLS, 2009; http:// www.scahls.org.au/Procedures/Documents/ANZSDP/Nematode_Parasites_of Ruminants_FINAL.pdf Accessed September 2014.

16. Lyndal-Murphy $M$, Pepper $P$, Delaney K. Determining resistance of ovine nematodes to anthelmintic treatments. In: Proceedings of the Australian Society for Parasitology, Gold Coast, QLD, Australia, 2006;108-109.

17. McCullagh P, Nelder JA. Generalized linear models. 2nd edn. Chapman and Hall, London, 1989.

18. Coles GC, Jackson, F, Pomroy WE et al. The detection of anthelmintic resistance in nematodes of veterinary importance. Vet Parasitol 2006;136:167-185.

19. Nielsen R. Drench resistance of sheep worms: New England region, New South Wales. Novartis Animal Health Update, Armidale, November 2012; http://worm mailinthecloud.files.wordpress.com/2012/11/nielsen-r-20121018-sheep-drench -resistance-new-england-nsw-2012-novartis-sponsored-update.pdf Accessed September 2014.

20. Walker E, Charman N, Kelly J, McClure S. Anthelmintic resistance survey in the central west LHPA. In: Proceedings of the 95th District Veterinarian's Conference, Armidale, NSW, 2013;18-24.

21. Baker KE, George SD, Stein PA et al. Efficacy of monepantel and anthelmintic combinations against multiple-resistant Haemonchus contortus in sheep, including characterisation of the nematode isolate. Vet Parasitol 2012;186:513-517. 22. Dobson RJ, Besier RB, Barnes EH et al. Principles for the use of macrocyclic lactones to minimise selection for resistance. Aust Vet $J$ 2001;79:756-761.

23. Le Jambre LF, Martin PJ, Johnston A. Efficacy of combination anthelmintics against multiple resistant strains of sheep nematodes. Anim Prod Sci 2010;50:946-952.

24. Dobson RJ, Le Jambre L, Gill JH. Management of anthelmintic resistance: inheritance of resistance and selection with persistent drugs. Int J Parasitol 1996;26:993-1000.

25. Dobson RJ, Hosking BC, Besier RB et al. Minimising the development of anthelmintic resistance, and optimising the use of the novel anthelmintic monepantel, for the sustainable control of nematode parasites in Australian sheep grazing systems. Aust Vet J 2011;89:160-166.

26. Pritchard RK, Hall CA, Kelly JD et al. The problem of anthelmintic resistance in nematodes. Aust Vet J 1980;56:239-250.

27. Abbott KA, Taylor M, Stubbings LA. Sustainable worm control strategies for sheep: a technical manual for veterinary surgeons and advisors. 4th edn. SCOPS, 2012. http://www.scops.org.uk/content/SCOPS-Technical-manual-4th -Edition-June-2012.pdf Accessed September 2014.

28. Flemming SA, Craig T, Kaplan RM et al. Anthelmintic resistance of gastrointestinal parasites in small ruminants. J Vet Intern Med 2006;20:435-444.

29. Sager H, Rolfe P, Strehlau G et al. Quarantine treatment of sheep with monepantel: rapidity of faecal egg count reduction. Vet Parasitol 2010;170:336339.

30. Walkden-Brown SW, Reeve I, Thompson L-J et al. Project Benchmarking Survey: a national survey of parasite control practices. In: Proceedings of the Australian Sheep Veterinarians 2006 Conferences (Wagga Wagga \& Hobart); 38-47. http://www.une.edu.au/research/research-centres-and-institutes/irf/ institute-publications/reports/?a=25611 Accessed September 2014.

31. Miller CM, Waghorn TS, Leathwick DM, Gilmour M. How repeatable is a faecal egg count reduction test? NZ Vet $J$ 2006;54:323-328.

32. Kaplan RM, Vidyashankar AN. An inconvenient truth: global worming and anthelmintic resistance. Vet Parasitol 2012;186:70-78.

33. Levecke B, Dobson RJ, Speybroeck $N$ et al. Novel insights in the faecal egg count reduction test for monitoring drug efficacy against gastrointestinal nematodes of veterinary importance. Vet Parasitol 2012;188:391-396.

34. Schroder J. Integrated Parasite Management of sheep: national overview of the need, available tools and the fit with industry. Anim Prod Sci 2010;50:74-75.

(Accepted for publication 24 November 2013) 